\title{
Aplicación de la ingeniería emocional (sensorial) por medio de la señalética en el Sistema de Bibliotecas de la UNMSM
}

Julio Yenque Dedios * Grimaldo Benítez Porras **

\section{RESUMEN}

El tema de investigación basada en la percepción sensorial que se relaciona con las innovadas tecnologías de la información y comunicación (TIC) detalla el empleo de un sistema de señalización bibliotecaria convencional y universal con el fin de obtener una óptima comunicación visual que permita una oportuna identificación, localización y orientación de las áreas como los servicios de información para presentar una mejora de la identidad corporativa, esto es, la buena imagen de la Biblioteca como organización ordenada y segura. Una vez descritos los antecedentes y aspectos teóricos se esboza un modelo de test aplicativo a los usuarios de Biblioteca con el software estadístico SPSS, diseñándose un programa de señalética bajo los estándares de seguridad recomendados para las bibliotecas. Como complemento se anexa un conjunto de símbolos, signos e íconos de uso frecuente y los rótulos temáticos de los cursos de las carreras profesionales que se estudian en esta Facultad.

Palabras clave: bibliotecas especializadas universitarias, comunicación visual, identidad corporativa, ingeniería emocional, ingeniería sensorial, señalética bibliotecaria

APPLICATION OF ENGINEERING THROUGH EMOTIONAL (SENSORY) SIGNALS IN THE LIBRARY SYSTEM UNMSM

\section{ABSTRACT}

Theme based on sensory perception innovated relates to information technology and communication (ICT) details the use of a conventional system librarian and universal signaling in order to obtain optimum visual communication allowing timely identification research , location and orientation of the areas as information services to present an improvement of corporate identity, that is, the good image of the library as a safe and orderly organization. Having described the background and theoretical aspects of applicative model of library users with the SPSS statistical software test outlines, a program of signage being designed under the recommended safety standards for libraries. Complementing a set of symbols, signs and icons often used is appended.

Keywords: corporate identity, emotional engineering, library signagem sensory engineering, visual communication, specialized university libraries

\section{INTRODUCCIÓN}

En esta sociedad globalizada procesamos la información que nos llega vía cognitiva; pero no valoramos la información que proviene de nuestros sentidos. Por ello, en el presente artículo se resalta el grado utilitario de la comunicación sensorial aplicado a las bibliotecas, a su vez, de contribuir con la buena imagen corporativa y seguridad ante dos sucesos resaltantes en nuestro ámbito educativo: la acreditación progresiva de los programas académicos de la UNMSM para cumplir con uno de los requisitos de la Nueva Ley Universitaria; y enfrentar la ocurrencia de un fenómeno natural previsible. Ante esta eventualidad, nosotros como agentes activos de la Unidad de Biblioteca de la Facultad de Ingeniería industrial, factor considerado en los estándares de calidad por el CONEAU y zona crítica dentro del marco de seguridad ante riesgos naturales (sismos e incendios) exponemos en el presente estudio la aplicación de la ingeniería sensorial (emocional) por medio de la señalética en el sistema de bibliotecas de la UNMSM, planteando lo siguiente:

\subsection{Objetivo general}

Proponer estrategias para la mejora continua en función de la imagen corporativa de las bibliotecas de la UNMSM velando por la seguridad y orden de sus recursos humanos, físicos y documentales.

\subsection{Objetivos específicos}

- Aplicar la ingeniería emocional a través de la señalética en las bibliotecas de la UNMSM como estrategia de mejora continua en la señalización de las zonas críticas (bibliotecas).

- Analizar el efecto sensorial por medio de la connotación visual que más aprecia el usuario cuando focaliza un punto de información.

- Crear un sistema estable y visible de señalización bibliotecaria para un eficaz acceso a los servicios de información.

\subsection{Antecedentes de la investigación}

Los orígenes de la comunicación visual como proceso responden a la necesidad que el hombre ha tenido de representar

\footnotetext{
* Ingeniero industrial. Docente Asociado de la Facultad de Ingeniería industrial, Dpto. Académico de Diseño y Tecnología Industrial de la UNMSM. E-mail: julio.yenque@industrial.unmsm.pe

** Bibliotecólogo. Jefe de Biblioteca de la Facultad de Ingeniería Industrial de la UNMSM. E-mail: grimaldo.benitez@industrial.unmsm.pe
} 
gráficamente conceptos (ideogramas) de personas, animales u objetos con el propósito de trasmitir pensamientos, necesidades y conocimientos e imponer este grupo de datos como lenguaje común (código) en su comunidad. Para ello, ha efectuado un proceso de comunicación gradual entre sus semejantes, emitiendo información por medio de representaciones visuales portadoras de conocimiento accesible para el emisor y receptor.

Asimismo, ha tenido la necesidad de usar su inteligencia visual o ingeniería emocional primigenia mediante la construcción de símbolos pictográficos para expresarse visualmente en un inicio antes del lenguaje articulado, sofisticado y convencional. Estas estructuras útiles de símbolos y signos a la fecha tienen reconocimiento universal como las señales de tránsito, símbolos astronómicos, entre otros.

El tratado de la ingeniería emocional relacionado con la señalética aplicado a las bibliotecas se viene efectuando desde finales del S.XX en países como Estados Unidos, destacando "Sistema de signos para bibliotecas" de Pollet y Haskellel (1979); en Inglaterra sobresale la obra "Guía de signos para bibliotecas" de Reynolds (1981); en España es relevante el estudio del "Estado de la señalética en la Biblioteca Pública de Valencia" de Barberá Montesinos (2009) y el artículo "señalización en la biblioteca" de Salaberría (1995); en Argentina resalta "Señalética una aplicación en bibliotecas" de Sánchez y Avillaneda (2005).

La señalética nace de la ciencia de la comunicación social o de la información y la semiótica para ser empleada en zonas masivas o de gran flujo humano.

Constituye una disciplina técnica que colabora con la ingeniería de la organización, la arquitectura, el acondicionamiento del espacio y la ergonomía bajo el vector del diseño gráfico. Se aplica, por tanto, al servicio y orientación de personas en un espacio o un lugar determinado, para la mejor y más rápida accesibilidad a los servicios requeridos y para una mayor seguridad en las acciones y sus desplazamientos.

\section{MARCO TEÓRICO}

\subsection{La ingeniería emocional}

La ingeniería emocional se conoce con el término japonés Kansei donde la sílaba kan significa sensitividad y sei significa sensibilidad. Este término, también adaptado como "ingeniería sensorial" o "usabilidad emocional", se usa para expresar la capacidad que tiene un objeto de despertar el placer en su uso, es decir la capacidad que tiene de motivar una respuesta de los sentidos del usuario, de enamorarlo, más allá del aspecto físico del producto o servicio.

Esta metodología, conocida como Kansei Engineering System (KES), fue desarrollada en los años 70 por el profesor Mitsuo Nagamachi, con el fin de incorporar el aspecto emocional al proceso de desarrollo ya sea de objetos de uso cotidiano, interfaces de usuario, software, etc.

\subsection{La señalización}

La palabra señalización, etimológicamente, proviene del latín sigma, señal, plural de signum, signo y del verbo facere, hacer, por lo tanto, su significado es hacer señales. De la palabra signalization se acuñó al español en 1970 con el término señalización, como tal recién se aplicó en el S.XVII. Correspondiendo a su finalidad, los términos verbales más usados para plantear objetivos particulares son: identificar, dirigir, informar, prevenir, orientar, guiar y persuadir.

Entre las funciones de la señalización destacan: Facilitar la comunicación, sistematizar los conjuntos de señales ya establecidos, contribuir a controlar la contaminación visual, ayudar a dirigir los movimientos de conjuntos, proporcionar información de distribución ordenada y segura de un lugar para hacer más fluida la circulación de personas en áreas internas y externa.

Del mismo modo, darle mayor utilidad a los servicios que se dan en una sociedad compleja, dinámica y difusa.

Los elementos fundamentales en un sistema de señales destacan diversos signos convencionales como: símbolos, señales, índices, pictogramas, códigos inherentes a ello, íconos, además de los grafitis.

Según Malmberg, las señales más comunes y efectivas se clasifican en cuatro grupos según la función que realizan:

a. Señales de prohibición. Limitan o impiden una acción.

b. Señales de advertencia. Evitar o prevenir algún riesgo o peligro.

c. Señales de mandato. Imperativos que no son disyuntivos.

d. Señales de indicación. Información direccional , que a su vez se subdivide o redunda en:

Señales direccionales e indicativos para lugares, informativos o instructivos y prohibitivos. [1] 
Las medidas de las señales deben ser grandes para que sean notorias, pero no exageradamente, y su tamaño debe ser congruente con el lugar en que se colocan o el tamaño de los objetos, dispositivos o materiales a los cuales fija. En todos los casos, el símbolo debe ser identificado desde una distancia segura. El área mínima $A$ de la señal debe estar relacionada a la más grande distancia $L$, a la cual la señal debe ser advertida por la fórmula siguiente: $A>=L 2 / 2000$ siendo $A$ el área de la señal en metros cuadrados y $L$ la distancia a la señal en metros. Esta fórmula es conveniente para distancias inferiores a $50 \mathrm{~m}$.

La técnica de carteles es de mucha ayuda cuando se quiere indicar el lugar adecuado y el número exacto de unidades que debe estar en un espacio determinado.

Estos carteles brindan apoyo en mantener limpio, ordenado, identificado y transitable toda planta bibliotecaria, facilitando el acceso para cada material, equipo o accesorio. En forma ordenada y segura debe ser colocada cada material debidamente clasificado. Para lograr el éxito con esta técnica se debe tener cuidado en el diseño, pues deben considerar información básica sobre características, capacidades y volúmenes de material documental en determinada área.

\subsection{La señalética}

Es parte de la ciencia de la comunicación visual que estudia el empleo de signos gráficos para guiar a las personas en un espacio determinado. Esta exige un código normalizado o lenguaje universal entre los usuarios para que la información llegue sin errores, fluida e instantánea al receptor.

Es la técnica que organiza y regula estas relaciones funcionales entre los signos de orientación en el espacio y el comportamiento de los individuos frente a los servicios que se encuentran a su disposición, actuando y desplazándose con seguridad.

En este sentido, la señalética responde a la necesidad de información o de orientación provocada por el fenómeno contemporáneo de la movilidad social (flujo de grupos de personas de distintas procedencias geográficas y variados caracteres socio culturales que se desplazan de un punto a otro por diversos motivos) y la proliferación de servicios públicos y privados.

Presenta las siguientes características que determinan su especificidad, tanto en su naturaleza, funciones, lenguaje y su técnica:

a. La comunicación señalética es efecto de la movilidad social. b. Es una disciplina técnica aplicada a la morfología especial, arquitectura urbana y a la organización de servicios públicos y del trabajo.

c. Su finalidad es la información oportuna y exacta.

d. Su principio es de la economía eficiente: máxima información con mínimos elementos y menor esfuerzo de localización y comprensión por parte del receptor (usuario o cliente).

e. Sus disciplinas y técnicas implicadas son el diseño gráfico de programas, planeamiento, arquitectura, ergonomía, medio ambiente y la producción industrial.

f. Se integra al espacio-ambiente y contribuye a promover una imagen de marca o servicio.

g. Su sistema de comunicación se estructura por un código universal de señales y signos.

h. Su estrategia de comunicación es la distribución lógica de mensajes fijos en sitios claves.

i. Su lenguaje es mono sémico, no discursivo, evitando toda retórica visual.

La señalética como la señalización debe ser clara, abundante y homogénea, permitiendo al usuario saber en todo momento dónde se encuentra y dónde puede dirigirse, así como conocer con facilidad lo que va a ubicar en las diversas secciones de la Biblioteca.

Se debe evitar la contaminación visual, priorizando la funcionalidad; en última instancia, se debe proporcionar el máximo de información en forma simple.

La señalética sirve para singularizar el espacio y distinguirlo de otros usos del edificio, pero no debe entrar en contradicción con la señalización general del resto de las instalaciones y, en la medida de lo posible, tampoco con la señalización sobre seguridad que esté impuesta por la normativa vigente.

\subsection{La infografía}

Es una técnica visual que pretende comunicar información a través de gráficos e ilustraciones de un modo claro, conciso, inmediato, atractivo, directo, perenne y objetivo, cuyo grado comprensivo tenga mayor impacto y acceso que la explicación verbal.

Sus elementos visuales como la simbología e iconografía pueden considerarse como herramientas de la señalética e ingeniería sensorial y/o emocional, pues sirven para atraer, aumentar y retener el interés informativo de los usuarios o utilizadores investigadores. 
En la actualidad, los mensajes de las infografías son más usados en las redes sociales a través de sus aplicaciones en formato estático o interactivo (imágenes en movimiento) que genera un efecto viral en los denominados "cibernautas".

\subsection{Diferencias entre la señalética y la señalización (cuadro 1)}

\begin{tabular}{|c|c|}
\hline SEÑALÉTICA & SEÑALIZACIÓN \\
\hline $\begin{array}{l}\text { 1. Rama del conocimiento que nace de la } \\
\text { comunicación social, por ello es más evolucionada. }\end{array}$ & $\begin{array}{l}\text { 1. Técnica empírica de poner señales a las cosas por } \\
\text { necesidad. }\end{array}$ \\
\hline $\begin{array}{l}\text { 2. Identifica, regula y facilita el acceso a los } \\
\text { servicios requeridos por las personas en un espacio } \\
\text { establecido. }\end{array}$ & $\begin{array}{l}\text { 2. Regula los flujos humanos, materiales o } \\
\text { motorizados en el espacio exterior. }\end{array}$ \\
\hline 3. Es un sistema más optativo de acciones. Las & humanas. \\
\hline  & 4. El sistema es universal y está creado como tal. \\
\hline 4. El sistema se crea y adapta en cada caso. & 5. Las señales preexisten a los problemas itinerarios. \\
\hline $\begin{array}{l}\text { 5. Las señales y las informaciones escritas son } \\
\text { consecuencia de los problemas precisos. }\end{array}$ & 6. El código de lectura se conoce a priori. \\
\hline 6. El código de lectura es conocido de modo parcial. & $\begin{array}{l}\text { 7. Las señales son materialmente normalizadas, } \\
\text { homólogas y se encuentran disponibles en la }\end{array}$ \\
\hline $\begin{array}{l}\text { 7. Las señales las homologa el diseñador del } \\
\text { programa para producirlas de modo especial. }\end{array}$ & $\begin{array}{l}\text { industria. } \\
\text { 8. Es indiferente a características del entorno. }\end{array}$ \\
\hline 8. Se supedita a las características del entorno. & 9. Aporta factores de uniformidad al entorno. \\
\hline 9. Aporta factores de identidad y diferenciación. & 10. No influye en la imagen del entorno. \\
\hline $\begin{array}{l}\text { 10. Refuerza la imagen pública o de marca de las } \\
\text { organizaciones. }\end{array}$ & 11. La señalización concluye en sí misma. \\
\hline $\begin{array}{l}\text { 11. Se prolonga en las actividades de identidad } \\
\text { corporativa. }\end{array}$ & 12. Tiene características generales libres. \\
\hline 12. Tiene características particulares controladas. & \\
\hline
\end{tabular}

Fuente: Adecuación propia.

\section{LA INGENIERIA EMOCIONAL EN LAS BIBLIO- TECAS A TRAVES DEL SENTIDO VISUAL}

La imagen e identidad corporativa con el diseño y decoración incide con la ingeniería emocional. Según el español Juan José Fuentes Romero, la decoración interior es importante porque crea un ambiente agradable e impone un estilo propio y, por otro, la accesibilidad facilita la localización de la Biblioteca y, sobre todo, permite el adecuado uso de sus servicios. [2]

En consecuencia, la decoración implica la adecuada estructuración de sus elementos como la iluminación, colorido y posición que deben armonizar con las señales en pos de llamar la atención y hacer sentir cómodo al usuario.

En la óptica del español Costa, el término "señalización" en el ámbito bibliotecario significa un sistema instantáneo e inequívoco de información por medio de señales visuales o mensajes espaciales de comportamiento de los recurrentes.
Correspondiendo a las necesidades de información y orientación que los usuarios adquieren al acudir a las instalaciones de la Biblioteca, por consiguiente, es necesario un acceso rápido a los servicios y mayor seguridad en el desplazamiento por sus ambientes.

Según Costa, un sistema de señalización es un conjunto de signos convencionales y señales normalizadas, o sea, estímulos de carácter cromático, figurativo, sensorial e icónico, creados por el hombre para facilitar la comunicación en las áreas de la Biblioteca. [3]

Orientando las acciones a los usuarios y tiene como objetivos guiar, dirigir, ambientar y proporcionar la distribución de la información de un lugar, así como facilitar la comunicación de áreas internas y externas de la Biblioteca. [4]

\section{Identidad o imagen corporativa como parte de la ingeniería emocional en las bibliotecas}

Un sistema de señalización resalta por su carácter informativo y orientador, además de funcionar como 
elemento eje en la imagen de identidad visual de la Biblioteca.

El término imagen corporativa se refiere al estilo que una Biblioteca adopta cuando enfrenta al exterior o público, es decir, la impresión que despierta en los usuarios.

Pero el término más usual es el de identidad corporativa, definido por Kirby, como la imagen pública de una organización que pugna por la apariencia y ser llamativa para entrar en la mente del usuario con una expresión global, clara y precisa por el uso variado de características visuales: rótulos o logotipos estandarizados, tipografía, escala de colores, decoración de interiores, tipo de mobiliario o construcción, entre otros. [5]

Musatti, consejero de Olivetti, en su Manual de imagen corporativa, describe que la imagen de una empresa no sólo se limita al diseño y publicidad de sus productos, relaciones laborales; también se refiere abstractamente a las "relaciones públicas". [6]

Porque la imagen es una expresión global o total, no basta con estar bien diseñado o tener buen impacto visual o estético, sino hay que añadirle un estilo social, pues las relaciones públicas entre el trinomio biblioteca-bibliotecario-usuario es muy intensa y constante por mantener una comunicación uniforme.

Según Kirby, para mejorar la identidad de la Biblioteca deben considerarse:

- La apariencia de la Biblioteca en la comunidad y su fácil reconocimiento por los usuarios.

- Comunicación de usuarios internos y servicios en términos de dirección e indicación activa para proveer recursos y resolver observaciones.

- Comunicación al personal bibliotecario sobre la localización de la organización estructural y sus objetivos. [7]

En un sistema de señalización inicial en pos de la identidad corporativa de una unidad de información dentro de su institución, en este caso de educación superior, se tiene:

1. En primer plano, el nombre de la Biblioteca como elemento identificador dentro del edificio,

2. En segundo plano se ubican los signos que orientan al usuario dentro de un espacio específico, tales como: vías de acceso, horario de servicio, información de los tipos de servicios, indicaciones normativas, circulación espacial en áreas, entre otros.

Por ello, es necesario que cada Biblioteca tenga su propia identidad, elaborando un logotipo distinto de sus servicios bibliotecarios.
El diseño involucra una serie de 3 actividades interdependientes, que según los especialistas del tema, son:

a. Planeamiento del sistema señalético.

b. Análisis de pictogramas, textos y colores.

c. Utilización del tipo de materiales.

El diseño abarca estos aspectos:

- Planificación del trabajo y selección de elementos que forman el sistema señalético.

- Definición de la imagen corporativa

- Descripción de la estructura del espacio (planos)

- Relación tamaño-distancia de señales

- Contraste de colores

- Análisis de factores ambientales

- Selección del tipo de materiales

- Producción y organización del sistema de señales. (Se ilustra en el cuadro 2)

\subsection{Control visual como parte de la ingeniería emocional}

Es un tipo de control que permite a cualquier persona (aun aquellas que tienen muy pocas nociones sobre el área de trabajo, e inclusive a visitantes) a reconocer a primera vista los estándares de seguridad y la información necesaria, para evitar algún posible accidente.

Dicho lenguaje visual generalmente es en base a rótulos escritos, con figuras o bien la combinación de ambos, que ayuda al trabajador en todo momento:

Lo alerta de alguna anormalidad, promueve su prevención, lo motiva o le advierte para que use su equipo de protección personal, lo orienta, lo dirige; le hace conciencia respecto al uso de su equipo de protección, le permite distinguir rápidamente entre lo que es normal y lo que no lo es, entre otros.

\section{Diseño de test sobre ingeniería emocional a los usuarios de Biblioteca}

Con el objetivo de medir el grado de satisfacción y ambiente cálido o agradable que experimentan los usuarios en los ambientes de Biblioteca, se hará una muestra aleatoria de 100 usuarios reales de Biblioteca de la Facultad de Ingeniería Industrial sobre el universo de todas las bibliotecas de la UNMSM, en forma conjunta sin distinguir sexo, edad o ciclo de estudios. 


\begin{tabular}{|c|c|}
\hline BIBLIOTECÓLOGO & DISEÑADOR GRÁFICO \\
\hline $\begin{array}{l}\text { 1. Identifica } \\
\text { necesidades } \\
\text { 2. Coordina el proyecto } \\
\text { 3. Analiza información } \\
\text { 4. Considera formatos } \\
\text { y presentación del } \\
\text { sistema } \\
\text { 5. Decide cantidad de } \\
\text { señales } \\
\text { 6. Supervisa gastos } \\
\text { 7. Asegura ejecución del } \\
\text { programa } \\
\text { 8. Es el intermediario } \\
\text { entre la Biblioteca y el } \\
\text { diseñador gráfico }\end{array}$ & $\begin{array}{l}\text { 1. Prepara costos } \\
\text { 2. Decide formatos } \\
\text { 3. Diseña y prepara } \\
\text { bocetos, signos, } \\
\text { 4. Prepara composición } \\
\text { tipográfica. } \\
\text { 5. Prepara impresión } \\
\text { enlace con el impresor. } \\
\text { 6. Emplea presupuesto } \\
\text { adecuadamente. } \\
\text { 7. Instala señales en los } \\
\text { puntos básicos. } \\
\text { 8. Evalúa funcionalidad } \\
\text { del sistema para hacer } \\
\text { cambios pertinentes. }\end{array}$ \\
\hline
\end{tabular}

Fuente: Adecuación propia.

A dichos usuarios en se les mostrará una serie de 80 fotografías sin leyenda de la Biblioteca de la FII, otras de una Biblioteca pública de provincia y otras extraídas del catálogo virtual de bibliotecas universitarias extranjeras, estas fotos representarán distintas situaciones: accesos, catálogos, contaminación visual, tipo de material visual, entre otros.

Cada usuario, deberá primero distinguir y establecer grupos de fotos según situaciones, características o necesidades similares o en su mismo contexto.

Luego deberá elegir entre 10 a 12 fotografías que más le impactaron favorablemente en orden de escala prioritaria y efecto visual. También elegirá otras 10 a 12 fotos que tuvieron efecto inverso o negativo.

Con esta muestra representativa, los responsables del test usando el software estadístico SPSS (versión recomendada) que ofrece un rápido entorno de modelación visual procesarán la información, manejando los datos y de un modo interactivo analizarán los resultados que determinarán estructurar gráfica o visualmente el ideal de Biblioteca que los usuarios desean tener integrando los aspectos físicos (infraestructura y mobiliario), materiales (textos impresos y digitales), humanos (calidad de atención en el servicio).

En contra parte, se tendrá las características negativas de Biblioteca que debemos evitar o superar en la etapa actual de acreditación académica.

\section{APLICACIÓN DE LA SEÑALIZACIÓN Y SEÑA- LÉTICA EN LAS BIBLIOTECAS}

Se trata de interpretar y valorar los significados bajo el enfoque bibliotecario, proceso básico para hallar la comunicación visual entre la información bibliográfica, el gestor y los beneficiarios.

En la bibliografía norteamericana, autores como Pollet y Haskell enfocan el diseño y programación de "Sistemas de signos para bibliotecas", quienes tratan en extenso y explícito la señalización y abordan aspectos teóricos y prácticos para guiar al bibliotecólogo en el diseño y producción de un eficiente sistema de señales exclusivo para este rubro.

Explican que el término "señalización" describe una ligazón a signos y otros elementos relacionados con el ambiente visual que trasmiten información; es un sistema de signos que identifica, orienta e informa dentro de organizaciones complejas como las bibliotecas, entre otras. [8]

Carol Brown sostiene que la señalización bibliotecaria es un importante y aún descuidado aspecto interior de un centro de documentación que abarca un conjunto de elementos que hacen accesibles las instalaciones de la Biblioteca, como las entradas, salidas y símbolos internacionales de acceso para apoyar a los usuarios en hallar el libre acceso a las colecciones y servicios. [9]

Linda Reynolds, en su obra: "Signs and guiding for libraries" analiza el estado del arte respecto a gráficos e identifica las dificultades para proporcionar una señalización adecuada a los usuarios. Puesto que la señalización es una forma esencial de comunicación entre el bibliotecario y usuarios, definiéndola como un sistema lógico y coherente de signos diseñado y construido con la seguridad de generar confianza para el desplazamiento en áreas. [10]

Para la autora inglesa el fino de un sistema de señales es coordinar la apariencia visual de signos (avisos, rótulos u otras publicaciones) y por medio de él crear una imagen unificada de la Biblioteca, pues existen diversos estilos gráficos en sus sistema de señalización.

Además, existen empresas españolas especializadas en la señalización y una de sus actividades más importantes es el diseño y fabricación de sistemas de señales para bibliotecas, que ha devenido en una búsqueda constante de soluciones a problemas de orientación espacial.

Así, la señalización bibliotecaria es un medio de ayuda en la localización de espacios y búsqueda 
documental que contribuye a crear identidad visual e imagen constituyendo un sistema de información pública que propicia la autonomía del usuario en tener el documento.

\subsection{Justificación para la creación de un sistema de señales en la Biblioteca}

Es importante identificar cada una de las secciones que conforman el centro bibliotecario y según estos contenidos y explicaciones justifiquen la necesidad de crear cada señal por estos motivos:

- Deficiencias de comunicación visual

- Instalaciones nuevas sin señalización

- Problemas que enfrentan el personal y los usuarios (investigadores, docentes, alumnos, administrativos y visitantes) al hacer uso de los servicios y acceder a los documentos bibliográficos, hemerográficos y digitales de la Biblioteca.

Carencia de un sistema de señalización uniforme y eficaz que identifique áreas y servicios.

\subsection{Tipología de signos para un sistema} señalizador de bibliotecas (cuadro 3 )

\begin{tabular}{|l|l|l|}
\hline \multicolumn{1}{|c|}{ TIPOS } & $\begin{array}{l}\text { SEÑALIZACIÓN } \\
\text { EXTERNA }\end{array}$ & $\begin{array}{l}\text { SEÑALIZACIÓN } \\
\text { INTERNA }\end{array}$ \\
\hline $\begin{array}{l}\text { Señalización } \\
\text { localización }\end{array}$ & $\begin{array}{l}\text { Planos, } \\
\text { directorios, signos } \\
\text { direccionales y de } \\
\text { identificación }\end{array}$ & $\begin{array}{l}\text { Planos, } \\
\text { indicaciones } \\
\text { direccionales } \\
\text { de áreas y } \\
\text { materiales } \\
\text { documentales. }\end{array}$ \\
\hline $\begin{array}{l}\text { Señalización } \\
\text { contenidos }\end{array}$ & $\begin{array}{l}\text { Indicaciones para } \\
\text { entrar y como } \\
\text { llegar a ella. }\end{array}$ & $\begin{array}{l}\text { Localización física } \\
\text { del documento, } \\
\text { identificación } \\
\text { del catálogo, } \\
\text { salas de lectura, } \\
\text { fotocopiado, etc. }\end{array}$ \\
\hline $\begin{array}{l}\text { Señalización } \\
\text { normativa }\end{array}$ & $\begin{array}{l}\text { Indicaciones } \\
\text { carácter general, } \\
\text { restrictivo y } \\
\text { regulativo }\end{array}$ & $\begin{array}{l}\text { Indicaciones } \\
\text { funcionamiento } \\
\text { de servicios, } \\
\text { recursos y } \\
\text { comportamiento. }\end{array}$ \\
\hline
\end{tabular}

Fuente: Adecuación propia.

\subsection{Proceso para desarrollar un programa señalético para bibliotecas (cuadro 4)}

I ETAPA: PLANEAMIENTO
$\begin{aligned} & \text { Analizar las condiciones del lugar, tanto el espacio } \\ & \text { como la señalización }\end{aligned}$

Revisar los planos arquitectónicos de instalaciones existentes y futuras.

Informarse sobre requerimientos de funcionamiento de instalaciones, áreas específicas, restricciones y circulaciones con apego a la imagen corporativa.

\section{ETAPA: ORGANIZACIÓN}

Determinar según la información los tipos de señales a estructurar.

Elaborar lista de señales definidas, palabras claves y equivalencias icónicas

Definir sobre los planos arquitectónicos los recorridos principales, accesos, salidas y determinar los puntos clave de la localización preliminar de las señales.

Revisión para aprobar señales de textos, iconografía y localización.

\section{ETAPA: DISEÑO}

Establecer la composición para las señales (tipografía, pictogramas, colores, materiales y tamaños).

Diseñar las señales aprobadas en la etapa precedente en forma de prototipos

\section{ETAPA: REALIZACIÓN}

Ordenar equipo y materiales en los que se producirá el sistema señalético

Desarrollo final de las señales según los fundamentos normativos de diseño y asesoramiento del diseñador gráfico.

Especificar los requerimientos para su elaboración profesional

Instalación de todas las señales

\section{ETAPA: SUPERVISIÓN}

Inspeccionar el trabajo del diseñador gráfico

Monitorear la instalación de las señales

Revisar y evaluar efectividad del sistema después de un período de funcionamiento

Efectuar los cambios y adecuaciones necesarias e indispensables.

Fuente: Adecuación propia. 


\section{Propuesta de un sistema integral de señales para las bibliotecas}

Esta propuesta consiste de modo básico en el planeamiento y diseño de íconos como textos representativos de las áreas internas y externas de la Biblioteca, así como de los grupos temáticos que integran la colección bibliográfica que preserva y desarrolla, una vez estructurados formarán un conjunto de señales con la función de actuar como un plano orientativo que facilite la identificación y localización de los servicios bibliotecarios.

Una vez determinadas las áreas a señalizar se procede a la selección de las palabras clave, las cuales tendrán un rol significativo en la señalización, de modo principal porque los términos deben ser descriptivos y legibles con el propósito de que el usuario los reconozca con facilidad; así se procederá a la traducción iconográfica con bocetos y medidas aproximadas de cada gráfico.

De este modo se obtendrá un sistema de señales idóneo para bibliotecas especializadas como de la Facultad de Ingeniería Industrial como una posible solución a los problemas de comunicación visual entre la Biblioteca y los usuarios.

En base al proceso anterior esta es la estructura de actividades a desarrollar:

Secuencia de actividades (Cuadro 5).

\begin{tabular}{|l|l|}
\hline \multicolumn{1}{|c|}{ I ETAPA: } & \multicolumn{1}{c|}{ II ETAPA: } \\
\hline $\begin{array}{c}\text { ZONAS ASPECTOS } \\
\text { A SENIZAR }\end{array}$ & \multicolumn{1}{c|}{\begin{tabular}{c}
\multicolumn{1}{c|}{ CLLECCIÓN DE PALABRA } \\
CLAVE
\end{tabular}} \\
\hline Acceso a la Biblioteca & $\begin{array}{l}\text { Biblioteca, directorio, entrada, } \\
\text { horario de servicio, }\end{array}$ \\
\hline Áreas administrativas & $\begin{array}{l}\text { Jefatura, área secretarial, } \\
\text { Responsable de: servicios } \\
\text { bibliotecarios, procesos } \\
\text { técnicos, Hemeroteca }\end{array}$ \\
\hline $\begin{array}{l}\text { Área de servicios } \\
\text { bibliotecarios }\end{array}$ & $\begin{array}{l}\text { Área de préstamo, Información } \\
\text { externa, Suministro } \\
\text { documentos, Consulta } \\
\text { general, DSI Consulta } \\
\text { B.D., referencia, Reserva, } \\
\text { reprografía }\end{array}$ \\
\hline Fondos bibliográficos & $\begin{array}{l}\text { Libros, revistas, obras } \\
\text { de referencia, informes, } \\
\text { Proyectos, monografías, Tesis, } \\
\text { CD }\end{array}$ \\
\hline Acceso a la colección & $\begin{array}{l}\text { Área catálogos, Kárdex } \\
\text { catálogo diccionario, catálogo } \\
\text { automatizado., }\end{array}$ \\
\hline $\begin{array}{l}\text { Area de procesos } \\
\text { técnicos }\end{array}$ & $\begin{array}{l}\text { Selección - adquisición, } \\
\text { Registro e ingreso } \\
\text { Catalogación clasificación, } \\
\text { Indización. } \\
\text { Publicaciones nuevas }\end{array}$ \\
\hline
\end{tabular}

\begin{tabular}{|l|l|}
\hline Área de hemeroteca & $\begin{array}{l}\text { Hemeroteca, nuevas } \\
\text { adquisiciones, Kárdex, Alertas } \\
\text { de revistas, Guías alfabéticas }\end{array}$ \\
\hline $\begin{array}{l}\text { Servicios internos de } \\
\text { espacio a los usuarios }\end{array}$ & $\begin{array}{l}\text { Sala de Lectura, Sala interna, } \\
\text { Testoteca, Sala de docentes, } \\
\text { Sala investigadores, } \\
\text { Cubículos de estudio }\end{array}$ \\
\hline Salidas Biblioteca & $\begin{array}{l}\text { Salida general y zonal, Salida } \\
\text { de emergencia }\end{array}$ \\
\hline Normas de área & $\begin{array}{l}\text { Reglamento de Biblioteca, } \\
\text { Reglas de seguridad. No } \\
\text { fumar, guardar silencio, No } \\
\text { introducir alimentos, Depósito } \\
\text { basura }\end{array}$ \\
\hline Medidas de seguridad & $\begin{array}{l}\text { Extinguidor, botiquín, zona } \\
\text { de peligro, ¿Qué hacer en } \\
\text { caso de sismo?, ¿Qué hacer } \\
\text { en un incendio?, Ruta de } \\
\text { evacuación, } \\
\text { Salida emergencia }\end{array}$ \\
\hline TERCERA ETAPA & $\begin{array}{l}\text { Sanitarios, guarda objetos, } \\
\text { Teléfono, WIFI, INTERNET. }\end{array}$ \\
\hline DervisEño DE SIGNOS
\end{tabular}

La presentación de este sistema de signos se estructura con:

Signos lingüísticos identificatorios

Pictogramas de áreas y servicios de Biblioteca

Gráficos representativos de las áreas temáticas

La dimensión de letreros, símbolos y retículas es uno de los elementos del diseño que requiere pruebas prácticas para determinar criterios de relación entre tamaño y distancia.

El Instituto Norteamericano de Artes Gráficas indica que las dimensiones de cada señal definen los niveles de agudeza visual de la persona para leer mensajes y el patrón referencial es de $2.54 \mathrm{~m}$ de altura para letras por cada $15 \mathrm{~m}$ de distancia para la visión. En cuanto a la extensión del punto de dirección de la flecha, debe considerarse un ángulo aproximado de $45^{\circ}$ para que sea legible.

La pauta de medición para la altura de letras se determina en $2.54 \mathrm{~cm}$ (pulgada) por cada $7.5 \mathrm{~cm}$ de distancia del observador y garantizar la claridad de la tipografía.

La medida total de retículas con los pictogramas y gráficos debe ser de $16 \mathrm{~cm}$ x lado, para que las dimensiones de los rótulos determinen su extensión, debe haber $2 \mathrm{~cm}$ de espacio entre el signo y la retícula.

En cuanto a la tipografía de los rótulos o letreros se suele usar el estilo helvético y el texto- fondo positivo en base a las medidas aproximadas resultantes del cálculo de las estimaciones propuestas.

Fuente: Elaboración propia 
Interpretación de colores reglamentarios (Cuadro 6)

\begin{tabular}{|l|l|}
\hline \multicolumn{1}{|c|}{ COLOR } & \multicolumn{1}{|c|}{ SIGNIFICADO } \\
\hline ROJO & $\begin{array}{l}\text { Prohibición, alto, identifica equipo } \\
\text { contra incendio }\end{array}$ \\
\hline AMARILLO & Prevención, alerta, riesgo \\
\hline VERDE & $\begin{array}{l}\text { Protección, primeros auxilios, visto } \\
\text { bueno autorizado }\end{array}$ \\
\hline CELESTE & $\begin{array}{l}\text { Obligación, información, } \\
\text { señalamiento de lugares y servicios }\end{array}$ \\
\hline
\end{tabular}

Fuente: Adecuación propia

Pictogramas de áreas y servicios de Biblioteca con más frecuencia de uso

Fuente: Adecuación propia

\section{IIII BIBLIOTECA}
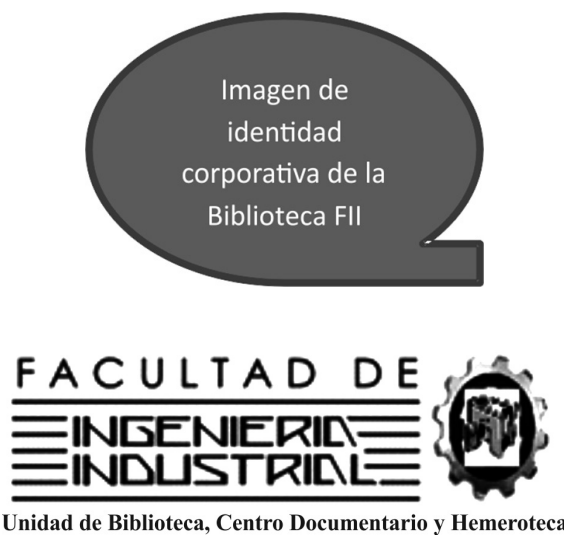

ACCESO A LA BIBLIOTECA. FIG. II (1-8)
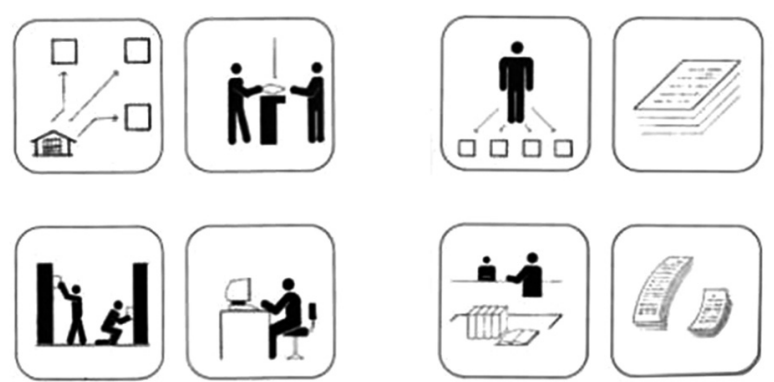

PROCESOS TÉCNICOS. FIG. III (9-16)
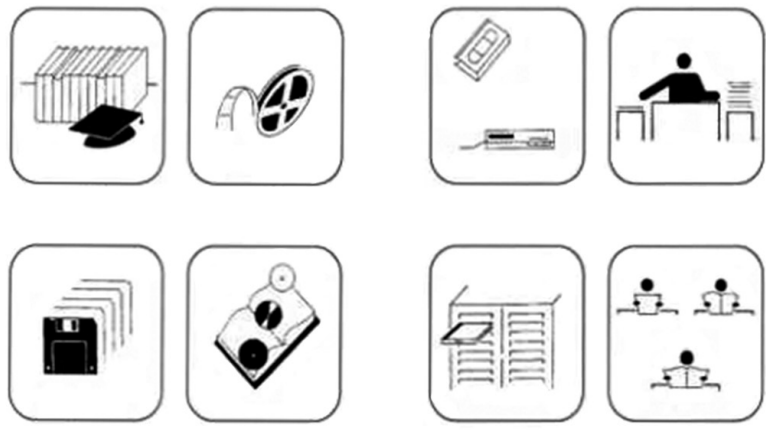

FONDOS BIBLIOGRÁFICOS. FIG. IV (17-24)
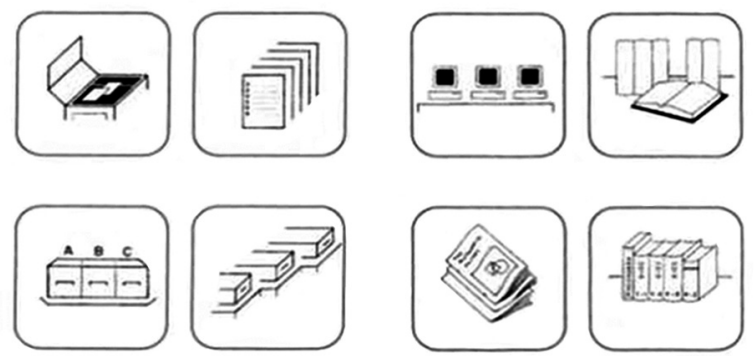

SERVICIOS BIBLIOTECARIOS. FIG. V (25-32)
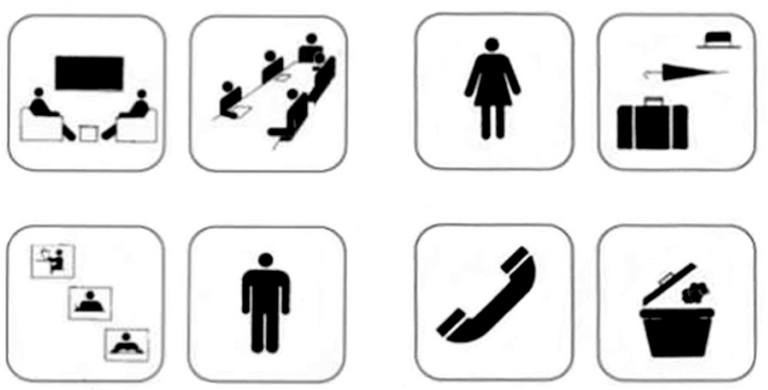

NORMAS ORDEN Y SEGURIDAD. FIG. VI (33-40)
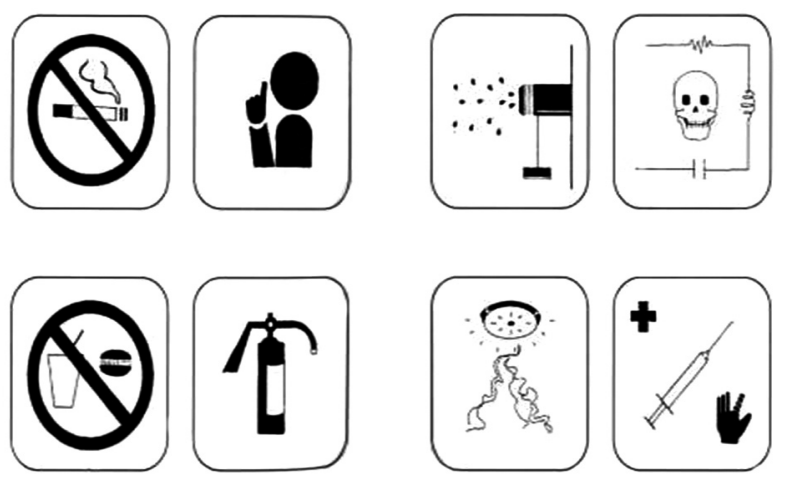


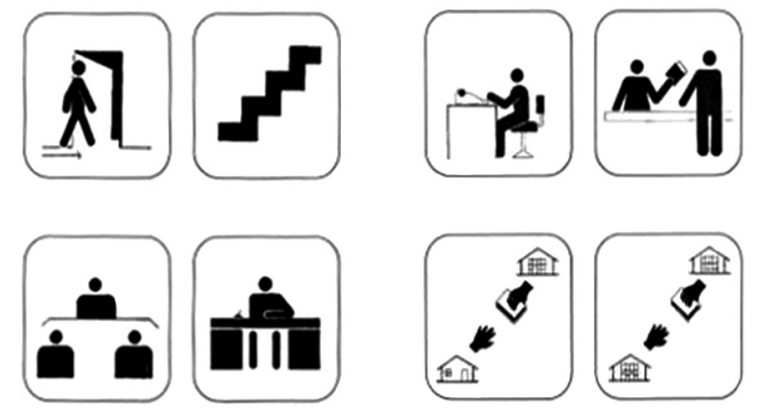

ZONAS PELIGRO Y SALIDA . FIG. VIII (49-56)
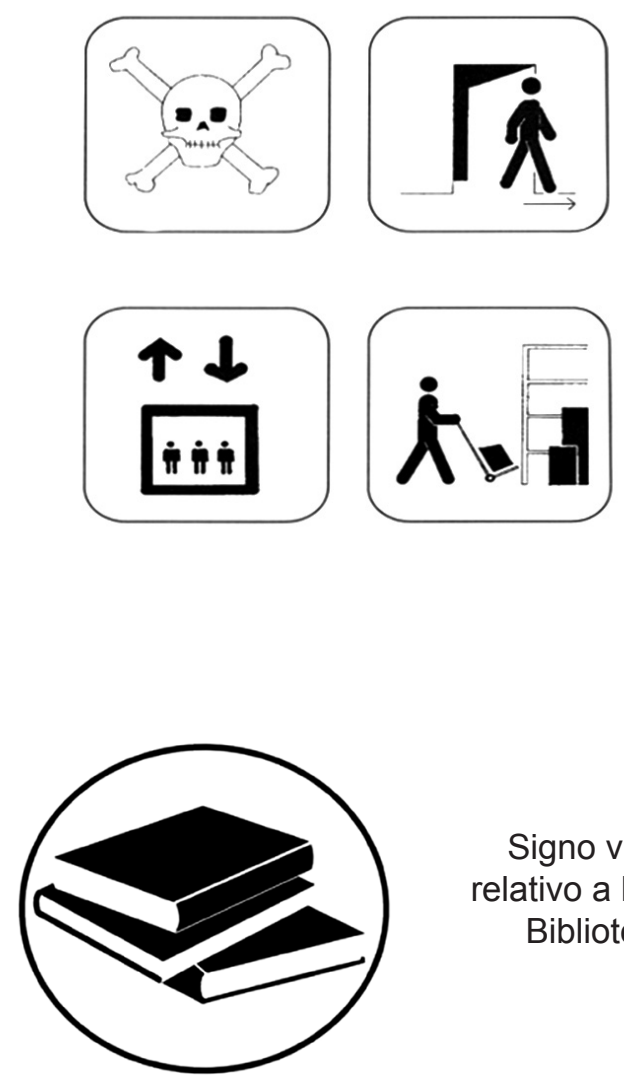

Signo visual relativo a libros y

Biblioteca
RÓTULOS DE ASIGNATURAS TEMÁTICAS SEGÚN ÁREAS ESPECIALIZADAS DE LA FACULTAD DE INGENIERÍA INDUSTRIAL

\section{Área de Producción y Gestión Industrial}

- Administración empresarial

- Administración estratégica

- Administración de negocios

- Comercio internacional
- Contabilidad empresarial

- Control de calidad

- Derecho empresarial

- Distribución de planta

- Elaboración y evaluación de proyectos

- Emprendimiento

- Ergonomía y mejora de procesos

- Estudio y medición del trabajo

- Finanzas

- Gerencia de finanzas

- Gerencia de operaciones

- Gerencia de recursos humanos

- Gestión de pequeñas y microempresas

- Gestión de proyectos

- Gestión del talento humano

- Gestión pública

- Ingeniería económica

- Ingeniería del producto

- Investigación de mercados y marketing

- Logística y cadena de suministros

- Marketing internacional

- Mercadotecnia

- Organización y administración industrial

- Psicología industrial

- Planeamiento estratégico y prospectiva

- Producción esbelta

- Planeamiento, programación y control de operaciones

- Sistemas de gestión de calidad

\section{Área de Diseño y Tecnología Industrial}

- Automatización industrial

- Base geométrico de diseño

- Dibujo asistido por computadora

- Dibujo de ingeniería

- Dibujo industrial

- Dibujo técnico

- Diseño industrial

- Geometría y diseño Industrial 
- Geometría descriptiva y diseño

- Gestión integral de taller metal mecánica

- Hidráulica y neumática industrial

- Ingeniería de materiales

- Mantenimiento industrial

- Máquinas y equipos

- Mecánica aplicada

- Operaciones de procesos unitarios

- Procesos de manufactura

- Programación de controladores lógicos programables (PLC)

- Resistencia de materiales

- Sistemas integrados de manufactura

- Tecnología industrial

- Termodinámica

\section{Área de Ingeniería de Sistemas e Informática}

- Algoritmos y estructura de datos

- Algoritmos y programación

- Base de datos y programación visual

- Desarrollo de aplicaciones web

- Diseño de experimentos

- Estadística aplicada

- Estadística industrial

- Estadística multivariante

- Estadística y probalidades

- Fundamentos de programación

- Informática

- Ingeniería de software

- Investigación operativa I-II

- Métodos estadísticos para la investigación

- Métodos computacionales para ingeniería

- Métodos numéricos

- Modelación y simulación de sistemas

- Sistemas de información gerencial

\section{Área de Seguridad y Salud en Trabajo}

- Accidentes y seguridad I-II

- Ambientes de trabajo I y II

- Auditoría ambiental
- Auditoría en seguridad y salud ocupacional

- Bioindicadores

- Bioquímica

- Cartografía y percepción remota

- Contaminación de aguas

- Contaminación de suelos

- Derecho y legislación ambiental

- Educación ambiental

- Edafología

- Elaboración de líneas base

- Evaluación de impacto ambiental I-II

- Fundamentos de ingeniería ambiental

- Gestión ambiental

- Geología general

- Geología ambiental

- Gestión de la seguridad integral

- Introducción a la ingeniería ambiental

- Introducción a la ingeniería de seguridad y salud en el trabajo

- Identificación de riesgos ambientales

- Manejo de cuencas

- Manejo de crisis

- Matemática aplicada a la ingeniería ambiental

- Mecánica de fluidos

- Medicina en el trabajo

- Meteorología y climatología

- Microbiología sanitaria

- Ordenamiento territorial

- Planificación ambiental

- Procesos de construcción

- Procesos mineros

- Protección y seguridad radiológica

- Remediación ambiental

- Saneamiento básico

- Saneamiento industrial

- Sistemas de seguridad ambiental

- Toxicología ambiental

- Tecnologías limpias

- Tratamiento de aguas residuales 


\section{Área de Ingeniería Textil y Confecciones}

- Acabado y terminación

- Análisis de hilos y telas

- Automatización de procesos

- Computación gráfica para diseño textil

- Control de calidad textil

- Diagnóstico y control de la contaminación del agua

- Fibrología

- Fundamentos de ingeniería ambiental

- Instrumentación industrial

- Introducción a la ingeniería textil

- Lavandería y proceso de prendas

- Moda y arte de vestir

- Proceso de confecciones

- Programación y software textil

- Serigrafía y estampado

- Tejido plano y de punto

- Textiles técnicos y geo textiles

- Tintorería

\section{Área de Ciencias Afines}

- Álgebra lineal

- Economía general

- Electricidad y electrónica industrial

- Expresión oral y escrita

- Física I-II

- Fisicoquímica

- Inglés básico

- Inglés intermedio

- Macroeconomía

- Matemática básica I-II-III

- Metodología de la investigación científica

- Metodología del trabajo intelectual

- Química general

- Química orgánica

- Sociología

- Taller de Tesis

- Tesis

\section{CONCLUSIONES}

1. La señalización bibliotecaria denota una actividad avocada al diseño, elaboración y colocación de un sistema de signos especiales que garantiza el acceso directo, rápido y autónomo a la información, pues guía las acciones y movilidad social de los usuarios, que incluye al personal bibliotecario, dentro de un entorno agradable visualmente por aplicación de la ingeniería emocional.

2. Una institución bibliotecaria que centre su acceso con señales facilita el cómodo ingreso desde el exterior hasta el interior de los ambientes, así como el adecuado traslado dentro de él y la más rápida identificación de materiales documentales por el personal y los usuarios.

3. La aplicación de la ingeniería emocional y/o sensorial a través de un plan de señalética propicia la mejora de identidad corporativa institucional.

4. La literatura escrita en inglés sobre señalización bibliotecaria es vasta y en ella se percibe el interés que se concede a los sistemas de señales tanto en empresas comerciales como en instituciones educativas, privadas y públicas con fines de orientación espacial y bibliográfica; a diferencia de la bibliografía en castellano que es limitada a pesar de lo importante que es la señalización como elemento orientador en instalaciones bibliotecarias.

5. El trabajo de test visual aplicado a una muestra de 100 usuarios alumnos de la Biblioteca FII indica que al $90 \%$ le impactaron positivamente las fotografías de bibliotecas extranjeras por el orden y espacio de sus ambientes; efecto inverso con las bibliotecas universitarias estatales peruanas, cuyas fotos fueron seleccionadas como muestra de ambientes desagradables donde predomina la contaminación visual, estrechez de espacios, desorden e inadecuada infraestructura.

6. Una Biblioteca sin un plan señalético atenta con la seguridad de los recursos humanos, físicos y materiales degradando la imagen institucional y la optimización de sus servicios de información.

\section{RECOMENDACIONES}

1. Emplear el sistema de controles visuales, colocando signos convencionales (pictogramas) en zonas estratégicas o puntos críticos para un óptimo acceso. 
2. Implementar técnicas y programas relacionada a la ingeniería emocional como las " $5 \mathrm{~s}$ " en la fase inicial del proceso de gestión de calidad para cada unidad administrativa y académica (Biblioteca).

3. Concientizar a los usuarios para evitar la contaminación visual, esto es, prohibir poner avisos no pertinentes sin estandarización en zonas no autorizadas como las paredes, puertas, muros. Incidir en el uso ordenado y estético de periódicos murales, vitrinas o paneles idóneos.

\section{REFERENCIAS BIBLIOGRÁFICAS}

[1] Barberá, C. (2009). Estudio del estado de la señalética en la Biblioteca Pública de Valencia y propuesta de una nueva metodología de estudio de servicios.

[2] Malberg, B. (2007). Teoría de los signos. 3. ${ }^{a}$ ed., Edit. s.XXI, México. [1]
[3] Munari, B. (1999). Diseño y comunicación visual. 2. ${ }^{a}$ ed., Edit.Gustavo Gili, Barcelona, España. [2-3]

[4] Sánchez, M. (2005). Señalética conceptos y fundamentos. 1. ${ }^{a}$ ed., Edit.Alfagrama, Buenos Aires, Argentina. [4-8]

[5] Sánchez, M. (2010). Señalética una aplicación en bibliotecas. Memorias de las Jornadas Mexicanas de Biblioteconomía. Vol. XXXIII, $\mathrm{N}^{\circ} .1[9-10]$

[6] riunet.upv.es/bitstream/handle/10251/29702/ Memoria.pdf?sequence $=1$ (visitado en abril-2014).

[7] biblioteca.universia.net/html_bura/ficha/ params/.../49447779.html (visitado en abril-2014)

[8] clubdelecturamexico.blogspot.com/.../sealticaconceptos-y-fundamentos- (visitado en abril-2014)

[9] www.elistas.net>Inicio $>$ Mise Listas bibliotecologos-cr. 